\title{
Long-term response of metastatic renal clear cell carcinoma following a subcutaneous injection of mixed bacterial vaccine: a case report
}

This article was published in the following Dove Medical Press journal: OncoTargets and Therapy

\author{
Jibing Chen' \\ Youyong Lv ${ }^{2}$ \\ Feng $\mathrm{Mu}^{\mathrm{\prime}}$ \\ Kecheng $X u^{\prime}$
}

'Fuda Cancer Hospital of Jinan University, Guangzhou 5I0665, China;

${ }^{2}$ Beijing Cancer Hospital of Peking

University, Beijing I00I42, China
Correspondence: Kecheng $\mathrm{Xu}$; Feng $\mathrm{Mu}$ Fuda Cancer Hospital of Jinan University, Guangzhou 510665, China

Email xukc@vip.I63.com; mufl318909@I63.com

\begin{abstract}
In this study, we present the case of a 56-year-old patient with renal clear cell carcinoma who developed lung metastases 13 months after nephrectomy and subsequently received tyrosine kinase inhibitor (sunitinib) and PD-1 antibody (nivolumab) immunotherapy, which failed to control the progression of the disease. The patient further developed metastases to the left pleura, bilateral hilar lymph nodes, liver, right lower kidney, scapula, left sixth rib, right tonsil, and other organs. There was severe anemia, requiring weekly blood transfusions. Karnofsky score was 30. After receiving mixed bacterial vaccine (MBV) consisting of 6 kinds of heat-inactivated bacteria plus Poly I:C, the patient's condition rapidly improved, systemic metastases gradually reduced in size or disappeared, anemia was corrected, and the patient was able to resume normal life and work. MBV treatment in the setting of failure of previous immunotherapy treatment appears to have achieved objective response for this patient with metastatic renal clear cell carcinoma, which has lasted more than 20 months.
\end{abstract}

Keywords: mixed bacterial vaccine, metastatic renal clear cell carcinoma

\section{Introduction}

Renal cell carcinoma ( $\mathrm{RCC}$ ) accounts for about $2 \%-3 \%$ of the adult malignant tumors. Pathologically, 75\% are clear cell carcinomas that do not respond well to conventional chemo- and radiotherapy. Although surgical resection is the preferred radical procedure, $25 \%-30 \%$ of the patients are diagnosed with disseminated metastasis, and nearly two-thirds of the patients undergoing radical surgery relapse within a few years. ${ }^{1-3}$

RCCs are considered candidates for target therapy because of their high frequency of somatic gene mutation. ${ }^{4}$ From the application of interferon (IFN) and interleukin-2 in the 1990s to drugs targeting small molecules and to immune checkpoint inhibitors, immunotherapies have been successively applied in RCC, especially in patients with metastatic disease, for which they are considered to be the only effective systemic treatment. Unfortunately, while these treatments have improved the response to treatment and slowed disease progression, complete response (CR) is rare. ${ }^{5}$

In this study, we present the case of a 56-year old Chinese patient with extensive metastatic clear cell renal carcinoma who was treated with interleukin-2, IFN, a small-molecule targeted drug, and PD-1 monoclonal antibody, with no response. After application of a mixed bacterial vaccine (MBV), the patient's metastatic lesions obviously shrank, and a clinical objective response lasting for more than 20 months was achieved. The patient remains disease-free and is reported as follows. 


\section{Case presentation}

The 56-year old Chinese patient underwent radical resection and was diagnosed with renal clear cell carcinoma (stage II) in 2015. Diagnosis of the disease was based on magnetic resonance (MR) imaging and pathological findings of kidney cancer $(6 \times 4 \mathrm{~cm}$, no lymphovascular invasion, sarcomatoid features, or necrosis), and there was no significant increase in tumor markers. After surgery, IL- 2 and IFN- $\alpha-2 b$ were administered for 2 months each. Lung metastasis was confirmed in April 2016 (Figure 1), and a tyrosine kinase inhibitor (Sunitinib) was administered for 3 months. The drug was discontinued after progression of lung metastasis was found. After cryosurgery for lung metastasis, an immune checkpoint inhibitor (nivolumab) was used for 2 months. Gross hematuria occurred in January 2017. Ultrasonography revealed space-occupying lesions in the bladder, and transurethral cystectomy was performed under general anesthesia. Postoperative pathology showed metastatic clear cell carcinoma. Later, imaging revealed metastases to the right pleura, right kidney, liver, left ribs, and right tonsil. The patient showed systemic fatigue, back and lower limb pain, difficulty walking, recurrent daily fever (around $38.5^{\circ} \mathrm{C}$ ), poor appetite, and emaciation. Peripheral blood erythrocyte count dropped below $3 \times 10^{12} / \mathrm{L}$ and hemoglobin below $100 \mathrm{~g} / \mathrm{L}$; the Karnofsky score was 30. After hospital admission, the patient received parenteral nutrition, blood transfusion, analgesics, and other symptomatic treatments. MBV treatment was started on April 12, 2017, after consultation with the patient and his family. This case report was approved by the ethics committee of Fuda Cancer Hospital, Jinan University and was in accordance with the Declaration of Helsinki; the patient's written informed consent including the images for publication was received for this study.

\section{Composition of MBV}

The MBV includes 6 kinds of heat-inactivated bacteria, namely 1) Pertussis bacillus (concentration 9 billion $/ \mathrm{mL}$ ), 2) Diphtheria bacillus endotoxin (concentration $20 \mathrm{Lf} / \mathrm{mL}$ ), 3) Tetanus bacillus endotoxin (concentration $5 \mathrm{Lf} / \mathrm{mL}$ ), 4) Typhoid bacillus (concentration of 300 million $/ \mathrm{mL}$ ), 5) Bacillus paratyphoid A/B (concentration 150 million/mL each), and 6) 10\% Staphylococcus aureus solution (concentration
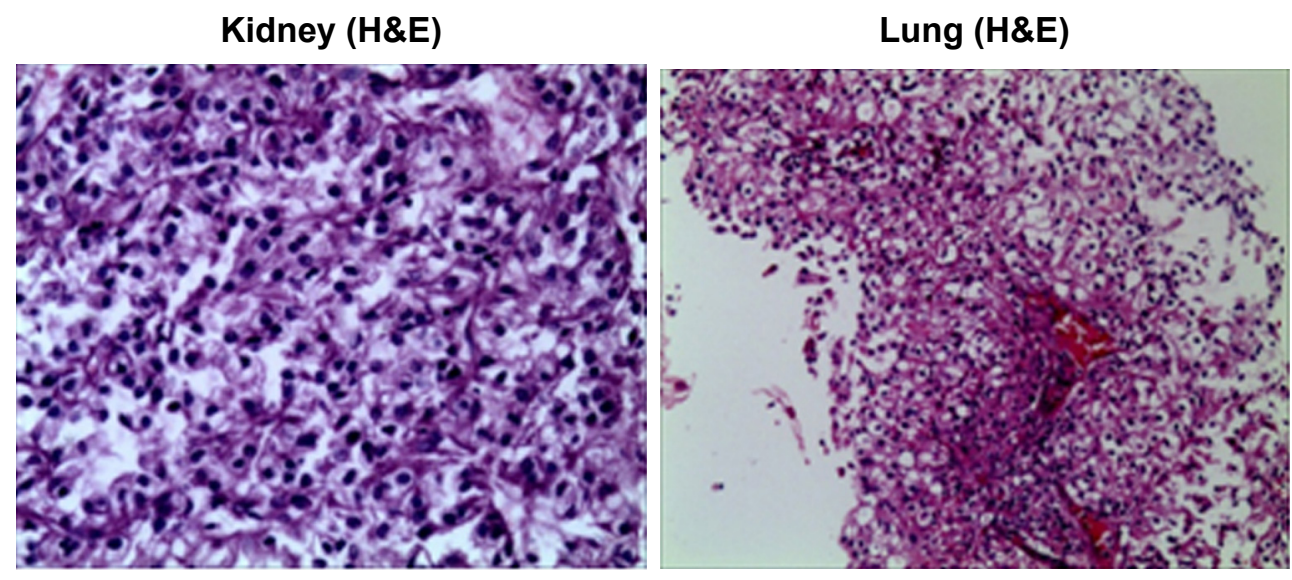

Lung (Cytokeratin)

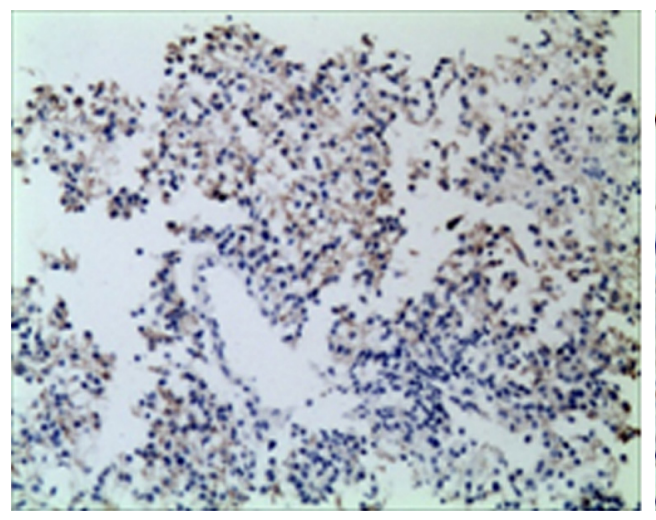

\section{Lung (Vimentin)}

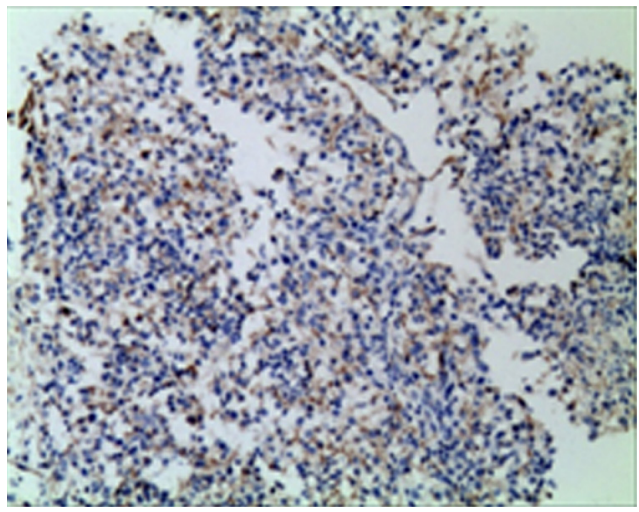

Figure I Pathologic detection of primary and metastatic lesions.

Notes: Clear cell carcinoma of kidney was diagnosed after surgery in April 2015. Lung metastasis was confirmed after fine needle biopsy in April 2016 (Cytokeratin++, Vimentin+++). 
1 billion/mL). Strains were purchased from National Institutes for Food and Drug Control. Zhejiang Weixin Biological Pharmaceutical Co., Ltd., was entrusted with technical service and culture of bacterial media. Additional additive included $0.1 \%$ Poly I:C (tlrl-pic; InvivoGen, San Diego, CA, USA) and 30\% fat emulsion for injection, blended in a certain proportion.

\section{Safety and curative evaluation Adverse events}

The most common adverse reactions recorded included local (injection site swelling and blisters) and systemic (chills, fatigue, and fever) reactions. Liver function was evaluated based on the levels of alanine transaminase (ALT), aspartate transaminase (AST), total bilirubin (T.BIL), and gammaglutamyl transpeptidase (GGT) multiple times during MBV treatment. Bone marrow hematopoietic function was evaluated based on the levels of peripheral blood erythrocytes and hemoglobin.

\section{Detection of lymphocyte subsets and cytokines}

Peripheral blood (2 $\mathrm{mL}$ ) was collected before and multiple times during MBV treatment for the detection of immune function. Flow cytometry (Facscanto $^{\mathrm{TM}} \mathrm{II}$; BD, Franklin Lakes, NJ, USA) was used for analysis. The analyzed indexes included the number and function of lymphocytes in the peripheral blood. The BD Multitest 6-color TBNK reagent (no 644611 ; BD) was used to detect the number of $\mathrm{CD}^{+} \mathrm{CD}^{+}$ cells (95\% range: $441-2,156$ cells $/ \mathrm{mL}$ ), $\mathrm{CD}^{+} \mathrm{CD}^{+}$cells (95\% range: $125-1,312$ cells $/ \mathrm{mL})$, total $\mathrm{CD}^{+}$cells $(95 \%$ range: $603-2,990$ cells $/ \mathrm{mL}$ ), and $\mathrm{CD}^{-}{ }^{-} \mathrm{CD} 16^{+} \mathrm{CD} 56^{+}$cells (95\% range: 95-640 cells/mL). The BD Cytometric Bead Array (CBA) Human Th1/Th2 Cytokine Kit II (no 551809; BD) was used to detect the expression of IL-2 (95\% range: 8-12.5 pg/mL), IL-4 (95\% range: $3.5-6 \mathrm{pg} / \mathrm{mL})$, IL-6 (95\% range: $2.7-8.5 \mathrm{pg} / \mathrm{mL})$, IL-10 (95\% range: $1.8-4 \mathrm{pg} / \mathrm{mL})$, TNF (95\% range: $1.7-2.5 \mathrm{pg} / \mathrm{mL})$, and IFN- $\gamma(95 \%$ range: $1.5-4 \mathrm{pg} / \mathrm{mL})$. The tests were performed according to the protocols given in the instruction manuals. Results above or within the reference range were considered to indicate normal immune function. One or more values below the reference range was considered to indicate immune dysfunction.

\section{Detection of circulating tumor cells (CTCs)}

Since no tumor markers can be used to evaluate tumor activity, CTCs were measured as a biomarker for the identification of patients at high risk of relapse and to monitor immune responses to therapy. According to our previously published reports, ${ }^{6-8} \mathrm{CD}^{-} 5^{-} \mathrm{CK}^{+} \mathrm{CD} 326^{+}$cells were defined as CTCs. In normal conditions, the reference number of CTCs is $0-1$ cells $/ 7.5 \mathrm{~mL}$ blood. CTCs $>5$ indicate poor prognosis and high risk of recurrence or metastasis. CTCs $<5$ indicate low risk of recurrence or metastasis. The detection procedure included collection of $7.5 \mathrm{~mL}$ blood from the patient and isolation of mononuclear cells using human peripheral blood lymphocyte separation solution (Haoyang Biological Manufacture Co., Ltd., Tianjin, China). Isolated cells were enriched by binding to magnetic CD326 (Ep-CAM) MicroBeads (Miltenyi Biotec Ltd., Bergisch Gladbach, Germany) using magnetic-activated cell sorting. Enriched cells were labeled with monoclonal antibodies targeting CD45, CD326, and CK (Miltenyi Biotec Ltd.) and counted by flow cytometry.

\section{MR imaging changes}

Changes in MR tumor imaging were monitored to evaluate the curative effect of MBV. According to the RECIST 1.1 guideline, ${ }^{9}$ therapeutic effect is categorized as a CR, disappearance of tumor detection of all target lesions; partial response (PR), total reduction in the diameter of the target lesions $\geq 30 \%$; stable disease (SD), tumor regression fails to reach PR or progressive disease (PD); or PD, total progression of the tumor diameter $\geq 20 \%$.

\section{Results}

\section{Evaluation of safety and curative effect}

On day 1 of treatment, $0.7 \mathrm{~mL}$ of MBV was delivered by subcutaneous injection into the arm; the patient was febrile to $38.5^{\circ} \mathrm{C}$ after injection, and fever spontaneously subsided after 2-3 hours. On day 2, there was mild local swelling at the injection site, and the patient was febrile to $38^{\circ} \mathrm{C}$ in the morning and afebrile by afternoon. On day 3 , an additional $1 \mathrm{~mL}$ of MBV was delivered. 12 hours after injection, local swelling and blisters appeared, and the patient's temperature rose to $38.8^{\circ} \mathrm{C}$ for 4 hours with associated chills, then recovered. The patient reported fatigue, which resolved with resolution of fever. Thereafter, $1 \mathrm{~mL}$ of MBV was administered every week. Ten days after the first MBV injection, the patient's symptoms began to improve, pain in the leg was reduced, the right tonsil mass decreased in size, and he was able to ambulate.

Three continuous injections of MBV constituted a cycle, after which treatment was stopped for a week and then repeated for long term (Table 1). During the injections, the patient reported only a few symptoms of cold chills, fever, or any other discomforts. After the treatment, liver function 
Table I Clinical details and therapeutic procedure

\begin{tabular}{|c|c|c|}
\hline \multicolumn{2}{|l|}{ Time } & \multirow{2}{*}{$\begin{array}{l}\text { Therapy } \\
\text { Surgery of left kidney, pathological diagnosis of RCC }\end{array}$} \\
\hline 2015 & April & \\
\hline & May-June & IL-2, subcutaneous injection $(20,000 \mathrm{IU} /$ day $)$ \\
\hline & July-August & IFN- $\alpha-2 b$ subcutaneous injection (3 million IU/2 days) \\
\hline \multirow[t]{3}{*}{2016} & April & Recurrence in right lung, fine needle biopsy to determine the tissue source \\
\hline & May-July & Sunitinib, taken orally (50 mg/day) for 4 weeks, stopped for 2 weeks, then repeated \\
\hline & August-November & Cryosurgery for lung metastasis and then Nivolumab intravenous injection $(3 \mathrm{mg} / \mathrm{kg})$ every 2 weeks \\
\hline \multirow[t]{9}{*}{2017} & January & Recurrence in bladder and surgery \\
\hline & March & Recurrence in right pleura, right kidney, liver, left rib, and right tonsil \\
\hline & April 12 & $\begin{array}{l}\text { Blood test: lymphocyte subsets, cytokines, and CTC } \\
\text { MR: sum of tumor long diameters } 21.7 \mathrm{~cm} \\
\text { Start of MBV treatment, } 0.7 \mathrm{~mL} \text { for Ist week }\end{array}$ \\
\hline & & $\begin{array}{l}\text { Symptomatic treatment in } 3 \text { days } \\
\text { Every } 3 \text { weeks of treatment ( } 1 \mathrm{~mL} / \text { week), rest for I week }\end{array}$ \\
\hline & April 22 & $\begin{array}{l}\text { Leg pain released obviously, walking ability recovered } \\
\text { Blood test: liver function and bone marrow parameters returned normal }\end{array}$ \\
\hline & June/July & $\begin{array}{l}\text { Blood test: lymphocyte subsets, cytokines, and CTC } \\
\text { Leg pain disappeared }\end{array}$ \\
\hline & August & Blood test: lymphocyte subsets and cytokines \\
\hline & September & Blood test: lymphocyte subsets, cytokines, and CTC \\
\hline & October & $\begin{array}{l}\text { Blood test: CTC } \\
\text { Right tonsil mass disappeared }\end{array}$ \\
\hline \multirow[t]{4}{*}{2018} & January & $\begin{array}{l}\text { Blood test: CTC } \\
\text { MR: sum of tumor long diameters } 15.2 \mathrm{~cm}\end{array}$ \\
\hline & August & MR: sum of tumor long diameters $7.5 \mathrm{~cm}$ \\
\hline & October & Blood test: lymphocyte subsets, cytokines, and CTC \\
\hline & December & Continuous tumor control "RP” for 20 months \\
\hline
\end{tabular}

Abbreviations: CTCs, circulating tumor cells; MBV, mixed bacterial vaccine; MR, magnetic resonance; RCC, renal cell carcinoma.

and bone marrow parameters recovered to normal levels and, to date, have remained within normal limits for more than 20 months (Figure 2).

During the follow-up of 20 months, the patient's lymphocyte subsets improved to normal range within the first 2 months and have remained stable (Figure 3A). The CTC count fluctuated and did not become undetectable until 20 months after treatment (Figure 3B). Serum Th1 cytokine levels remained normal, whereas Th2 cytokine levels returned to normal after 3 months of treatment and thereafter continued to remain normal (Figure 3C).

\section{MR imaging changes}

Three months after initiation of MBV treatment, the patient reported complete resolution of limb pain. Six months after initiation of treatment, the right-sided tonsil mass disappeared (Figure 4). Before treatment, the sum of the long diameters at the 4 metastatic sites was $21.7 \mathrm{~cm} ; 8$ months after MBV treatment, the sum was $15.2 \mathrm{~cm}(30 \%$ reduction, PR); and 16 months after treatment, the sum was $7.5 \mathrm{~cm}(65.4 \%$ reduction, PR) (Figure 5). Through the end of December 2018, no tumor recurrence has been found (very similar with the MR examination of 16 months and figures not attached). The patient appears completely normal (Karnofsky score $100)$ and has returned to daily work.

\section{Discussion}

Cancer has been treated with nonspecific immunotherapy for more than a century using bacterial products, whose original form was called Coley toxin. In 1989, Coley, who was later known as the father of tumor immunotherapy, observed a patient with sarcoma who could not be operated on, and the tumor disappeared completely after infection with streptococcus pyogenes. Subsequently, Coley treated 896 sarcoma patients with a combination of heat-inactivated streptococcus pyogenes and Serratia and observed a 5-year survival rate reaching $34 \%-73 \%$ among this cohort. ${ }^{10}$

Using a retrospective cohort design with external controls, Richardson et al ${ }^{11}$ compared 128 Coley cases treated in New York from 1890 to 1960 with 1,675 patients treated with 
A
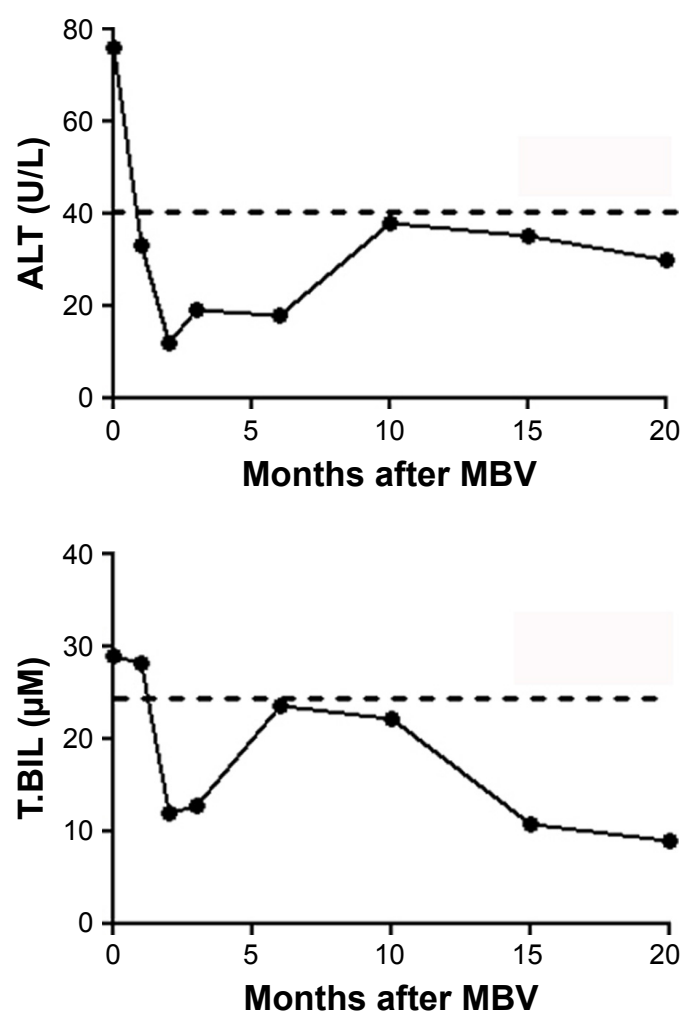

B

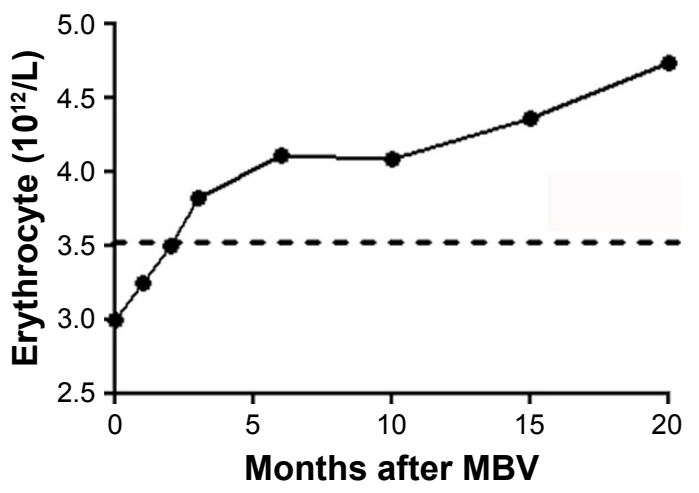

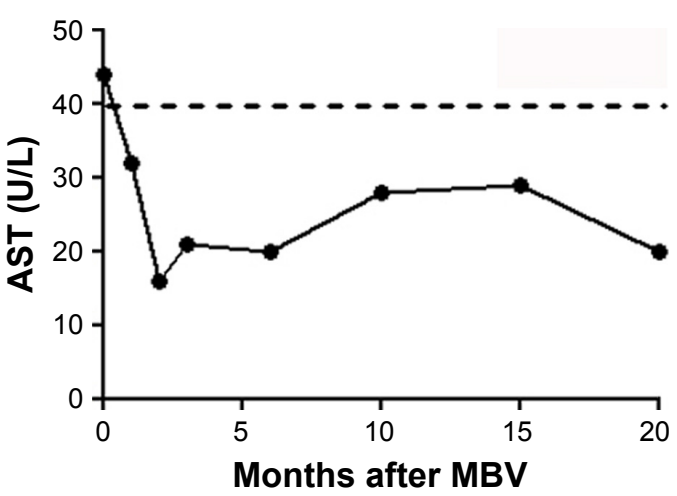
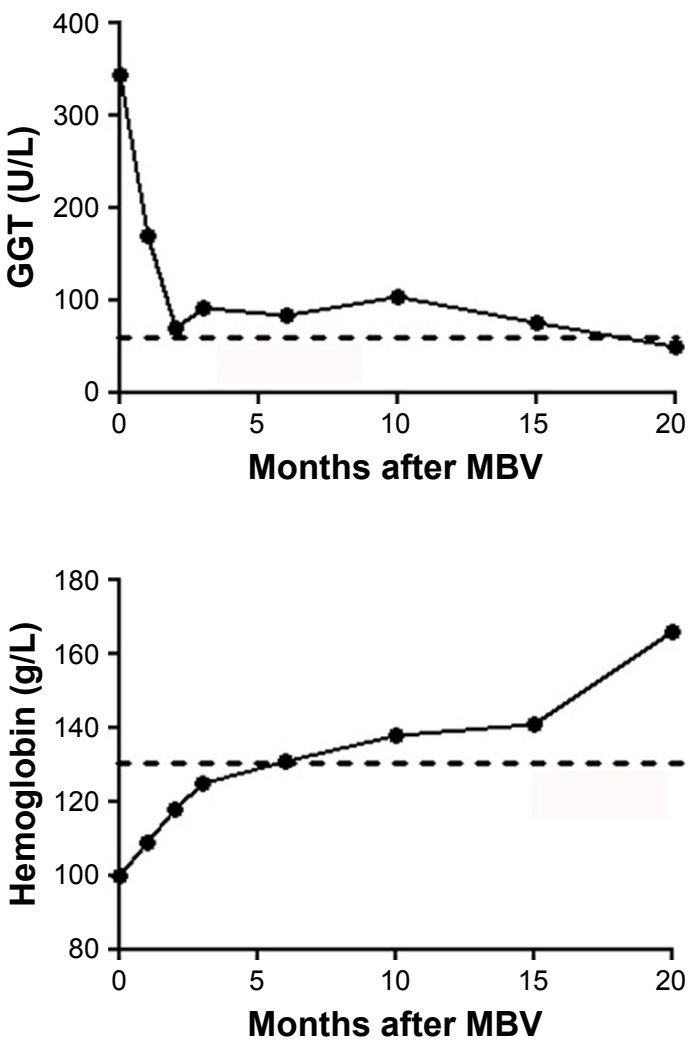

Figure 2 The patient's liver and bone marrow function recovered with time.

Notes: The dotted lines represent limits of the normal reference range. (A) For indexes of liver function, the detection values below the dotted line are normal. (B) For indexes of bone marrow function, the detection values above the dotted line are normal.

Abbreviations: ALT, alanine transaminase; AST, aspartate transaminase; GGT, gamma-glutamyl transpeptidase; MBV, mixed bacterial vaccine; T.BIL, total bilirubin.

modern standards of care. They found that the median survival time of patients treated using Coley toxin was 8.9 years, whereas that of patients treated using modern standards of care was 7 years. Approximately, $50 \%$ of the sarcomas treated with Coley toxin survived 10 years, compared with $38 \%$ of those treated with modern treatments. ${ }^{11}$ Meanwhile, Richardson et al ${ }^{11}$ also found that Coley toxin can improve 10-year survival in patients with kidney and ovarian cancers. In 2013, DeWeerdt ${ }^{12}$ proposed that, even in accordance with today's clinical evaluation standards, the therapeutic effect of Coley toxin regimen is noteworthy.
The patient described here had received various modern treatments after renal clear cell carcinoma recurrence, including cytokines, chemotherapy, molecular targeted drugs, and PD-1 antibody therapy, but still demonstrated progression of widespread metastases, severe anemia, and poor systemic condition. After MBV treatment, the patient's general state rapidly improved, the metastatic lesions gradually reduced in size within 20 months, and no new metastasis was found.

Over the years, there have been many different names for Coley toxin preparations (eg, Vaccinin, Novopyrexal, 

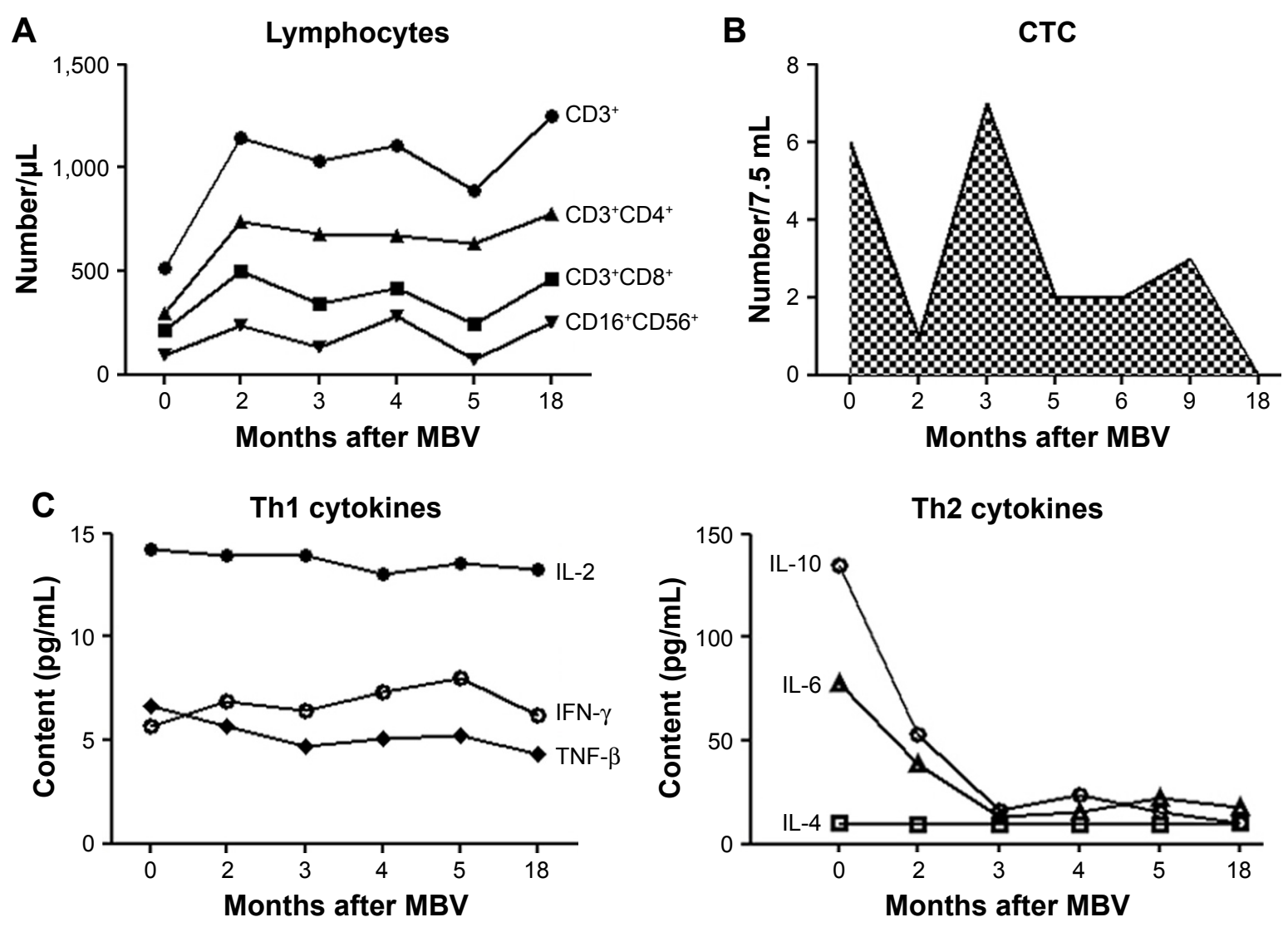

Figure 3 Changes in CTCs and cytokines associated with tumor progression over time.

Notes: (A) Lymphocytes associated with cytotoxic tumor activity. (B) CTCs associated with the risk of tumor recurrence; the fluctuating shadowed area represents changes in CTC count in the blood. (C) ThI and Th2 cytokine levels over time.

Abbreviations: CTCs, circulating tumor cells; MBV, mixed bacterial vaccine.

MBVax, and others), which are difficult to use in humans in modern times. Therefore, we selected 6 bacterial ingredients that may have similar mechanism to make the vaccine according to the reports in the literature and to produce a mixed vaccine (called MBV) for cancer patients who cannot undergo surgery and do not respond to radiation and chemotherapy. The bacteria and toxins we use have been found to have immune-boosting effects. Pertussis bacillus contains CyaA, an invasive adenylate cyclase that activates specific $\mathrm{CD} 8^{+} \mathrm{T}$ cell immunity; ${ }^{13,14}$ Diphtheria toxin can specifically deplete regulatory $\mathrm{T}$ cells without affecting the activity of other effector T cells; ${ }^{15}$ Tetanus toxin can significantly promote the bi-directional transfer of dendritic cells (DC) and activate the activity of $\mathrm{CD} 4{ }^{+} \mathrm{T}$ cells; ${ }^{16}$ Typhoid bacillus is a facultative anaerobe with inherent oncolytic properties that strongly activates the innate immune system (such as increasing TNF- $\alpha$ levels) and further activates adaptive immunity; ${ }^{17-19}$ Salmonella can promote the cross-presentation of tumor antigen by DC cells and generate effector anti-tumor $\mathrm{CD} 8^{+} \mathrm{T}$ cells, ${ }^{20}$ cause tumors to shrink, and promote survival in animal models; ${ }^{21}$ Poly I:C is a toll-like receptor 3 activator, which can directly promote the anti-tumor activity of DC and
T cells, inhibit the proliferation of various tumor cells, and induce apoptosis. ${ }^{22}$ According to our observations, our MBV preparation may have the following characteristics: 1) can enhance the patient's physique and improve liver and bone marrow functions; 2) increase the number of lymphocytes and reduce the number of CTCs; 3 ) maintain the expression level of Th1 cytokines and significantly reduce the content of Th2 cytokines; and 4) promote atrophy and even disappearance of metastatic foci. The patient described in this case study was only observed for 20 months, and the longer-term efficacy still waits for further follow-up. There are other bacterial or toxin formulations to choose from, which may vary from tumor to tumor, pending further study and trial.

As a complex disease, cancer is characterized by pathological heterogeneity and genomic instability, resulting in inefficient response to the existing monotherapy regimens. ${ }^{23}$ The aim of using various bacterial vaccines is to activate different immune factors and cells to fight and kill cancer cells, analogous to the Chinese old statement that "thousands of troops improvise, adjust to changing circumstances." The therapeutic effect achieved for the patient described here after MBV treatment was rapid and durable and significantly superior 


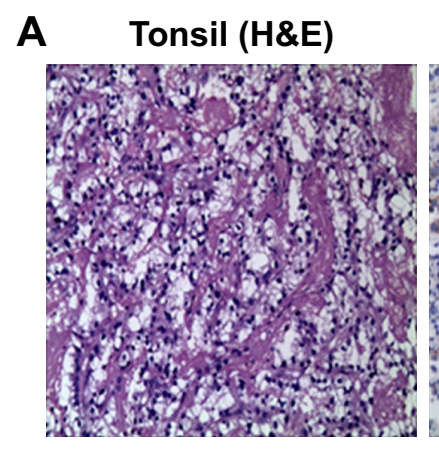

B
Cytokeratin

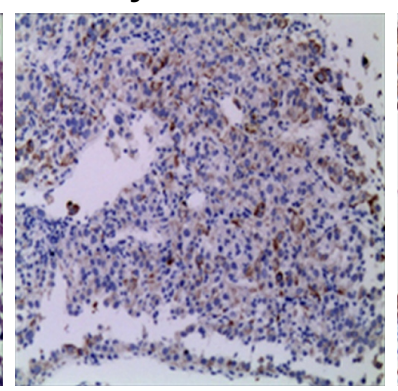

Vimentin

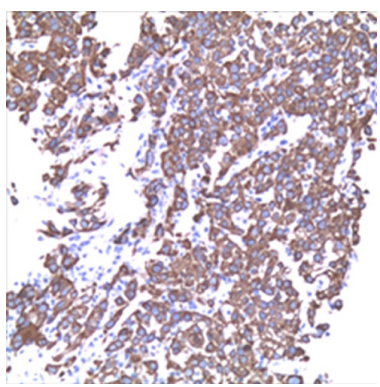

\section{6 months after MBV}
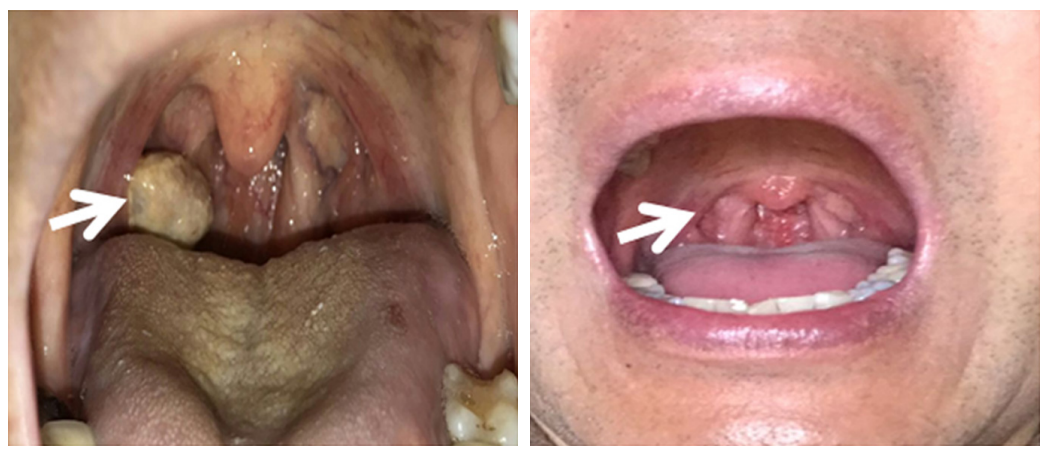

Figure 4 Tonsil metastasis before and after MBV treatment.

Notes: (A) Histological examination of tonsil mass. (B) Gross view of tonsil mass before and after MBV treatment (white arrows indicate the tonsil mass). Abbreviation: MBV, mixed bacterial vaccine.
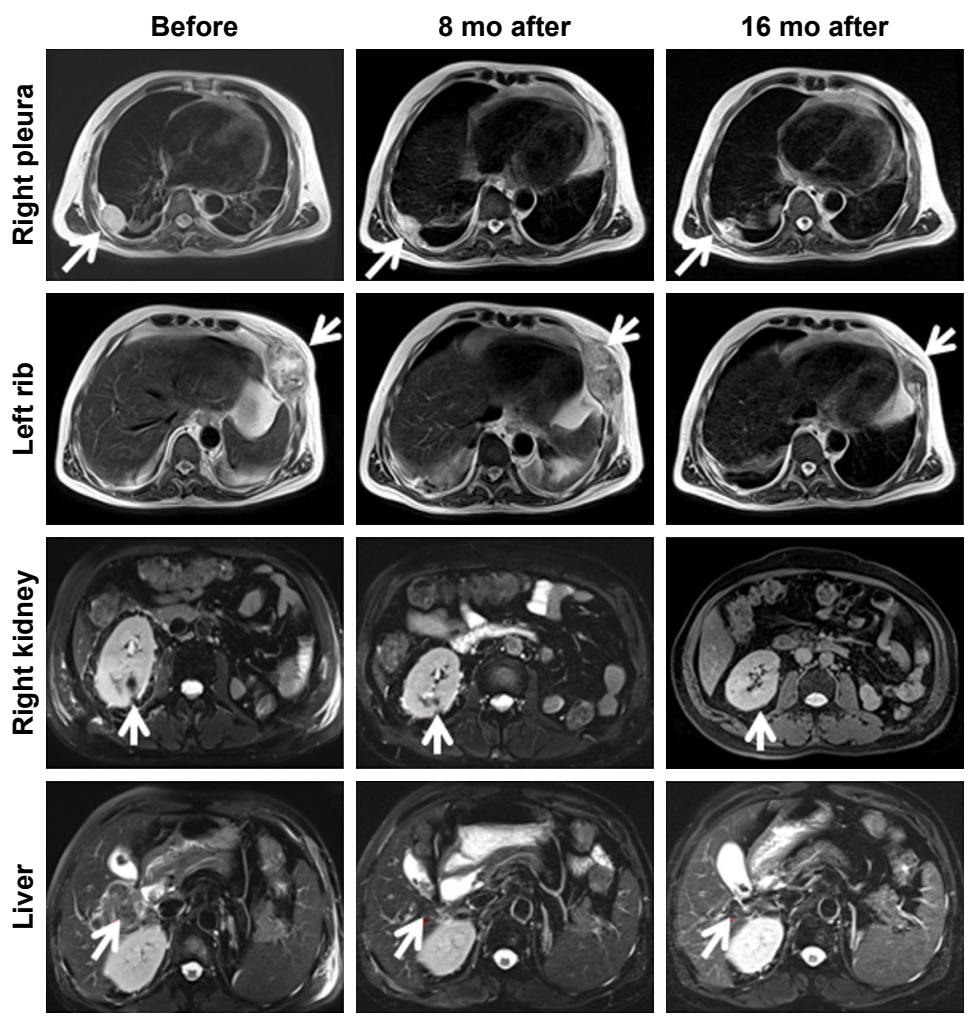

Figure 5 MR imaging findings at different time points before and after MBV treatment.

Notes: For right pleural metastasis, the size was $5.4 \times 4.4 \mathrm{~cm}$ (before), $3.9 \times 3 \mathrm{~cm}$ ( 8 months after), and I.6 $\times 1.4 \mathrm{~cm}$ (I6 months after), respectively. For left rib metastasis, the size was $7.3 \times 6.3 \mathrm{~cm}$ (before), $4.8 \times 3 \mathrm{~cm}(8$ months after), and $1.9 \times 1.1 \mathrm{~cm}(16$ months after), respectively. For right kidney metastasis, the size was $3.8 \times 3.6 \mathrm{~cm}$ (before), $2.9 \times 2.2 \mathrm{~cm}$ ( 8 months after), and $2.1 \times 1.5 \mathrm{~cm}(16$ months after), respectively. For liver metastasis, the size was $5.2 \times 4.3 \mathrm{~cm}($ before $), 3.6 \times 3.2 \mathrm{~cm}(8 \mathrm{mo}$ after $)$, and $1.9 \times 1.8 \mathrm{~cm}$ (16 months after), respectively. White arrows indicate the tonsil mass.

Abbreviations: MBV, mixed bacterial vaccine; MR, magnetic resonance; mo, months. 
to the results afforded by current conventional treatment methods, which is worth further observation and analysis.

\section{Disclosure}

The authors report no conflicts of interest in this work.

\section{References}

1. Kabaria R, Klaassen Z, Terris MK. Renal cell carcinoma: links and risks. Int J Nephrol Renovasc Dis. 2016;9:45-52. doi:10.2147/IJNRD.S75916

2. Bergmann L, Beck J, Bothe K, et al. Treatment algorithm for metastatic renal cell carcinoma-recommendations based on evidence and clinical practice. Oncol Res Treat. 2014;37(3):136-141. doi:10.1159/000360179

3. Albiges L, Choueiri T, Escudier B, et al. A systematic review of sequencing and combinations of systemic therapy in metastatic renal cancer. Eur Urol. 2015;67(1):100-110. doi:10.1016/j.eururo.2014.04.006

4. Motzer RJ, Hutson TE, McCann L, Deen K, Choueiri TK. Overall survival in renal-cell carcinoma with pazopanib versus sunitinib. $N$ Engl J Med. 2014;370(18):1769-1770. doi:10.1056/NEJMc1400731

5. Schadendorf D, Hodi FS, Robert C, et al. Pooled analysis of long-term survival data from phase II and phase III trials of ipilimumab in unresectable or metastatic melanoma. J Clin Oncol. 2015;33(17):1889-1894. doi:10.1200/JCO.2014.56.2736

6. Shi J, Li Y, Liang S, et al. Analysis of circulating tumor cells in colorectal cancer liver metastasis patients before and after cryosurgery. Cancer Biol Ther. 2016;17(9):935-942. doi:10.1080/15384047.2016.1210731

7. Shi J, Li Y, Liang S, et al. Circulating tumour cells as biomarkers for evaluating cryosurgery on unresectable hepatocellular carcinoma. Oncol Rep. 2016;36(4):1845-1851. doi:10.3892/or.2016.5050

8. Lin M, Alnaggar M, Liang SZ, et al. Using circulating tumor cells to evaluate the efficacy of irreversible electroporation for unresectasble pancreatic cancer. Immunol Res. 2018;66(1):172-178. doi:10.1007/s12026017-8959-2

9. Eisenhauer EA, Therasse P, Bogaerts J, et al. New response evaluation criteria in solid tumours: revised RECIST guideline (version 1.1). Eur J Cancer. 2009;45(2):228-247. doi:10.1016/j.ejca.2008.10.026

10. Coley WB. Treatment of inoperable sarcoma by bacterial toxins (the mixed toxins of the Streptococcus erysipelatis and the Bacillus prodigiosus). Proc R Soc Med. 1910;3(Sug Sect):1-48.

11. Richardson MA, Ramirez T, Russell NC, Moye LA. Coley toxins immunotherapy: a retrospective review. Altern Ther Health Med. 1999;5(3): $42-47$.
12. DeWeerdt S. Bacteriology: a caring culture. Nature. 2013;504(7480): S4-S5. doi:10.1038/504S4a

13. Fayolle C, Ladant D, Karimova G, Ullmann A, Leclerc C. Therapy of murine tumors with recombinant Bordetella pertussis adenylate cyclase carrying a cytotoxic T cell epitope. J Immunol. 1999;162(7):4157-4162.

14. Dadaglio G, Morel S, Bauche C, et al. Recombinant adenylate cyclase toxin of Bordetella pertussis induces cytotoxic T lymphocyte responses against HLA*0201-restricted melanoma epitopes. Int Immunol. 2003; 15(12):1423-1430.

15. Fisher SA, Aston WJ, Chee J, et al. Transient treg depletion enhances therapeutic anti-cancer vaccination. Immun Inflamm Dis. 2017;5(1): 16-28. doi:10.1002/iid3.136

16. Mitchell DA, Batich KA, Gunn MD, et al. Tetanus toxoid and CCL3 improve dendritic cell vaccines in mice and glioblastoma patients. Nature. 2015;519(7543):366-369. doi:10.1038/nature14320

17. Grille S, Moreno M, Bascuas T, et al. Salmonella enterica serovar Typhimurium immunotherapy for B-cell lymphoma induces broad antitumour immunity with therapeutic effect. Immunology. 2014;143(3): 428-437. doi:10.1111/imm.12320

18. Toneri M, Miwa S, Zhang Y, et al. Tumor-targeting Salmonella typhimurium A1-R inhibits human prostate cancer experimental bone metastasis in mouse models. Oncotarget. 2015;6(31):31335-31343. doi:10.18632/oncotarget.5866

19. Zhao M, Geller J, Ma H, Yang M, Penman S, Hoffman RM. Monotherapy with a tumor-targeting mutant of Salmonella typhimurium cures orthotopic metastatic mouse models of human prostate cancer. Proc Natl Acad Sci U S A. 2007;104(24):10170-10174. doi:10.1073/pnas. 0703867104

20. Avogadri F, Martinoli C, Petrovska L, et al. Cancer immunotherapy based on killing of Salmonella-infected tumor cells. Cancer Res. 2005; 65(9):3920-3927. doi:10.1158/0008-5472.CAN-04-3002

21. Zhao M, Yang M, Ma H, et al. Targeted therapy with a Salmonella typhimurium leucine-arginine auxotroph cures orthotopic human breast tumors in nude mice. Cancer Res. 2006;66(15):7647-7652. doi:10. 1158/0008-5472.CAN-06-0716

22. Bianchi F, Pretto S, Tagliabue E, Balsari A, Sfondrini L. Exploiting poly(I:C) to induce cancer cell apoptosis. Cancer Biol Ther. 2017; 18(10):747-756. doi:10.1080/15384047.2017.1373220

23. von Rundstedt FC, Necchi A. Current markers and their value in the era of immuno-oncology. Transl Androl Urol. 2017;6(6):1111-1116. doi:10.21037/tau.2017.11.11
OncoTargets and Therapy

\section{Publish your work in this journal}

OncoTargets and Therapy is an international, peer-reviewed, open access journal focusing on the pathological basis of all cancers, potential targets for therapy and treatment protocols employed to improve the management of cancer patients. The journal also focuses on the impact of management programs and new therapeutic agents and protocols on
Dovepress

patient perspectives such as quality of life, adherence and satisfaction. The manuscript management system is completely online and includes a very quick and fair peer-review system, which is all easy to use. Visit http://www.dovepress.com/testimonials.php to read real quotes from published authors. 